\title{
Comparison Between Botulinum Toxin A Injection and Lacrimal Punctal Plugs for the Control of Post- LASIK Dry Eye Manifestations: A Prospective Study
}

\author{
Sameh M. Fouda · Hala K. Mattout
}

Received: December 11, 2016 / Published online: February 2, 2017

(C) The Author(s) 2017. This article is published with open access at Springerlink.com

\begin{abstract}
Introduction: Laser in situ keratomelieusis (LASIK) is one of the commonest refractive procedures performed nowadays. The dry eye problem is nearly universal in all patients after LASIK and it can be so annoying that the post-operative patient satisfaction is sometimes precluded. Conventional treatment includes the use of artificial tears. Alternative methods such as punctal plugs and botulinum toxin injection can be used for the management of post-LASIK dry eye. The aim of this study is to compare botulinum toxin injection in the orbicularis muscle to lacrimal punctal plugs for the control of post-LASIK dry eye manifestations.

Methods: This is a prospective study that included 60 patients who had LASIK eye surgery for correction of refractive errors. Patients were randomly assigned to one of three methods of dry eye management; the first method was conventional medical treatment with preservative-free tear substitutes only (group A: 20 patients $=40$
\end{abstract}

Enhanced content To view enhanced content for this article go to http://www.medengine.com/Redeem/B58 7F0603FC2D5E3.

S. M. Fouda $(\bowtie) \cdot$ H. K. Mattout

Ophthalmology Department, Faculty of Medicine,

Zagazig University, Zagazig, Egypt

e-mail: samehfouda2006@yahoo.com eyes); the second method was intraoperative injection of botulinum toxin A (BTA) in the orbicularis muscle below the lower punctum of both eyes (group B: 20 patients $=40$ eyes) and the third method was intraoperative insertion of temporary extended duration silicone punctal plugs in the lower punctum of both eyes (group C: 20 patients $=40$ eyes).

Results: In the first follow-up visit after 2 weeks, the two test groups $(\mathrm{B}, \mathrm{C})$ showed a statistically significant increase in both tear film break up time (TBUT) and Schirmer test score with a decrease in the OSDI score and daily frequency of lubricants used in comparison to the control group A. These differences were maintained in the next follow-up visit but they became statistically insignificant at the 3rd and 6th post-operative months. Complications were encountered more in the punctal plug patients $(60 \%)$ than in BTA patients $(25 \%)$ and this difference was statistically significant.

Conclusion: The use of BTA injection to control dry eye symptoms by inducing temporary punctal ectropion is an effective method to improve patient satisfaction after LASIK eye surgery. It has higher level of patient satisfaction and fewer complications in comparison to punctal plugs or topical standard dry eye treatment.

Keywords: Botulinum toxin; Dry eye; Lacrimal plugs; LASIK 


\section{INTRODUCTION}

Laser in situ keratomelieusis (LASIK) is one of the commonest refractive procedures performed nowadays. It involves the creation of a superficial corneal flap by the microkeratome followed by application of an excimer laser to ablate a pre-determined amount of corneal stroma correcting the refractive error and thus improving the visual acuity $[1,2]$.

The dry eye problem is nearly universal in all patients after LASIK and it can be so annoying that the post-operative patient satisfaction is sometimes precluded. It presents immediately after the procedure with burning sensation, ocular discomfort and even reduction of post-operative visual acuity if the dry eye keratopathy affected the central cornea. It results from the temporary corneal neurotrophic status that occurs upon severing the corneal nerves during flap creation, thus interrupting the corneal lacrimal gland reflex. The condition usually starts to improve over the first post-operative month and it shows nearly complete resolution over the first post-operative year [2, 3]. Conventional treatment includes the use of artificial tears that act as a lubricating agent at the ocular surface [4]. Alternative methods such as punctal plugs and botulinum toxin injection can be used for the management of post LASIK dry eye.

Botulinum toxin is a potent neurotoxin produced by the bacterium Clostridium botulinum which elaborates eight antigenically different exotoxins (A, B, C1, C2, D, E, F and G). They all share the property of interfering with the release of acetyl choline at the neuromuscular junctions and thus resulting in a temporary paralysis of the muscle that ends after about 4 months when new nerve terminal sprouts extend towards the muscle surface [5-7]. The commercially available botulinum toxin preparations belong to serotypes $\mathrm{A}$ and $\mathrm{B}$ $[8,9]$.

Lacrimal drainage system plugs are known to improve the signs and symptoms of moderately dry eyes that are not improved with topical lubrication, and they are usually well-tolerated [10]. They can be classified according to their location (punctal versus canalicular) and their duration of placement (short versus extended duration). They represent a relatively safe option for the management of dry eye disease but some complications have been reported such as extrusion, migration, canaliculitis, epiphora, chronic irritation and allergic reaction. They can be classified into temporary short duration plugs that are usually made of animal collagen and last for 4-14 days, and temporary extended duration plugs that last from 2 to 6 months and they are made of different materials that include silicone, hydrogel, polydioxanone and acrylic. The temporary extended duration punctal plugs are the type used following refractive surgery [10-13].

The aim of this study is to compare botulinum toxin injection in the orbicularis muscle to lacrimal punctal plugs for the control of post-LASIK dry eye manifestations.

\section{METHODS}

This is a prospective study that included 60 patients who had LASIK eye surgery for correction of refractive errors. The procedure was performed by the same surgeon (Fouda S), and the flap was created using a Moria $M 2^{\circledR}$ microkeratome with 90 or 120 blades according to the measured pre-operative central corneal thickness. Laser treatment was done using an Excimer laser (192 nm UV laser) of a Schwind Amaris $500 \mathrm{E}^{\circledR}$ machine (Schwind eyetech solution, Germany). All procedures followed were in accordance with the ethical standards of the responsible committee on human experimentation (institutional and national) and with the Helsinki Declaration of 1964, as revised in 2013. Informed consent was obtained from each patient before Botox injection and punctal plugs application. All procedures were performed between February 2015 and April 2016 in a private eye center in Egypt.

All patients received pre-operative full medical and ocular history taking, full ophthalmic examination, corneal imaging and tear secretion tests. Exclusion criteria were 
pre-operative dry eye, ocular surface irregularities, neuromuscular disorders prohibiting botulinum toxin injection, e.g. myaethenia gravis, or patients with known hypersensivity to botulinum toxin.

Dry eye was assessed by both subjective and objective methods. Eye discomfort was assessed using an ocular surface disease index (OSDI). An OSDI questionnaire was used to quantify the dry eye symptoms. Subjects were asked questions regarding the symptoms of dry eye that they had experienced during a 1-week recall period; the OSDI questions comprised three different subscales: ocular symptoms, vision-related functions, and environmental triggers and each answer was scored on a four-point scale ranging from zero (no problems) to four (significant problem). Responses to all of the questions were combined to generate an OSDI score that ranged from 0 to 100 using the OSDI formula: OSDI $\odot=$ sum of scores $\times 25 /$ number of questions answered. The OSDI scores and the level of ocular disability were categorized on a 4-class scale ranging from none (OSDI total score $\leq 12$ ) to severe (OSDI total score $\geq 33$ ) $[14,15]$. Tear break-up time (TBUT) and the Schirmer tear secretion test were used to objectively evaluate the tear film before performing the refractive surgery and post-operatively in all follow-up visits.

The sample size was calculated through Epi-Info (Epidemiological Information Package) software version 6.1. The improvement rate for dry eyes was $83.3 \%$ with injection of botulinum toxin and the improvement rate for dry eyes in the punctual plugs group was $50.0 \%$ [25]. So, at $95 \%$ confidence interval and power of study $80 \%$, the sample size was calculated to be 60 patients.

Patients were randomly assigned to one of three methods of dry eye management; the first method was conventional medical treatment with preservative-free tear substitutes only (group A: 20 patients $=40$ eyes); the second method was intraoperative injection of botulinum toxin A (BTA) in the orbicularis muscle below the lower punctum of both eyes (group B: 20 patients $=40$ eyes) and the third method was intraoperative insertion of a temporary extended duration silicone punctal plug in the lower punctum of both eyes (group C: 20 patients $=40$ eyes).

All patients were instructed to put preservative-free tear substitute eye drops (polyethylene glycol and propylene glycol) Systane ultra $^{\circledR}$ (Alcon Laboratories, Inc., Fort Worth, TX, USA) as needed and the frequency was recorded in a special chart. Antibiotic eye drops of Ofloxacin $0.3 \%\left(\right.$ Oflox $^{\circledR}$; Allergan corporation, Irvine, CA, USA) and anti-inflammatory eye drops in the form of fluorometholone $\left(\mathrm{FML}^{\circledR}\right.$; Alcon Laboratories, Inc, Fort Worth, TX, USA) were used in the first 2 weeks in all patients.

Group B patients were injected with 3.75 units $(0.15 \mathrm{ml})$ of botulinum toxin at the end of the LASIK procedure using a 28-gauge insulin needle. The injection site was subcutaneous in the orbicularis muscle of the lower lid $2 \mathrm{~mm}$ below the lower punctum to induce punctal ectropion and thus interfering with the normal tear drainage pathway and improving dry eye manifestations. BTA $\left(\right.$ Botox $^{\circledR}$, Allergan $^{\circledR}$ Corporation, Westport, Mayo, Ireland) comes in a vial containing 100 units of freeze-dried BTA. It was reconstituted and diluted with $4 \mathrm{ml}$ of saline, resulting in a concentration of 25 units $/ \mathrm{ml}$ (2.5 units $/ 0.1 \mathrm{ml})$. Before starting the LASIK procedure, percutaneous anaesthesia was induced by applying a eutectic mixture of local anaesthetics (EMLA ${ }^{\circledR}$ cream) over the site of injection to avoid any undesired pain response that may unstabilize the LASIK flap. The site and dose of botulinum toxin injection were chosen based on the previous work of Salhin et al. [18].

Silicone punctal plugs (FCI Ophthalmics, Inc., Paris, France) were inserted in the lower punctum in both lower eyelids at the end of the LASIK procedure in group $\mathrm{C}$ patients.

The patients' data were reported at 2 and 6 weeks and 3 and 6 months post-operatively. The main outcome measures included tear film stability as per the TBUT test, tear secretion per the Schirmer's test and dry eye symptoms per the OSDI questionnaire and the tear substitute daily frequency by a simple daily chart. The 
TBUT test was considered positive for dry eye when the break in the pre-corneal tear film appeared within less than $10 \mathrm{~s}$ following fluorescein dye instillation, and a positive Schirmer's test was considered when the amount of the Schirmer strip wetting was less than $5 \mathrm{~mm}$ after $5 \mathrm{~min}$ with pre-test instillation of one drop of benoxinate hydrochloride $0.4 \mathrm{mg}$ $\left(\right.$ Benox $^{\circledR}$-Eipico, Egypt) as a local anaesthetic.

Data were checked and analyzed by using SPSS for Windows (version 16, SPSS, Chicago, IL, USA). We checked normality and for normally distributed data, we used the mean \pm SD and the parametric ANOVA test, and for not normally distributed data, we used the median (range) and the non-parametric Kruskal-Wallis test. For all analyses, a $P$ value of $<0.05$ was considered statistically significant.

\section{RESULTS}

A total of 60 patients (120 eyes) were included in this study; they all had uncomplicated LASIK refractive surgery for correction of refractive errors. Pre-operative errors included myopia, hypermetropia and astigmatism. The spherical equivalent for all patients ranged from $+4 \mathrm{D}$ to $-8.5 \mathrm{D}$ with a mean of $4.25 \pm 2.5 \mathrm{D}$. There were 34 female patients and 26 male patients and they were distributed as follows: 11 females to 9 males in group A (control), 12 females to 8 males in group B (BTA group) and 13 females to 7 males in group $C$ (plugs group). The age of the patients was $27.5 \pm 2.25$ years in group $\mathrm{A}$, $26.2 \pm 5.11$ years in group $B$ and $27.9 \pm 4.7$ years group C. No statistically significant difference existed among the three groups regarding their pre-operative TBUT, Schirmer test results or OSDI scores.

In the first follow-up visit after 2 weeks, the two test groups (B, C) showed a statistically significant increase in both tear film break up time (TBUT) and Schirmer test score with a decrease in the OSDI score and daily frequency of lubricants used in comparison to the control group A. These differences were maintained in the next follow-up visit but they became statistically insignificant at the 3rd and 6th post-operative months. Table 1 shows the treatment results in every follow-up visit.

Complications were encountered more in the punctal plug patients $(60 \%)$ than in BTA patients $(25 \%)$ and this difference was statistically significant. Among patients treated with punctal plugs, complications included irritation (30\%) and extrusion (30\%). $25 \%$ of patients treated with BTA reported complications in the form of increased ocular irritation $(15 \%)$ in the first 2 weeks that was relieved by artificial tears and disappeared nearly completely after the first 2 weeks; moreover, 2 patients (10\%) reported decreased blinking power manifested by entrance of soap in the eye during face washing in the morning. Table 2 demonstrates the complications among both treatment groups.

The overall patient satisfaction was higher among patients receiving botulinum toxin injection with effective control of dry eye and few side-effects. Among the 20 patients treated with BTA, 5 of them requested repetition of injection after the 6-month duration of follow-up due to residual post-LASIK dry eye manifestations, while none of the punctal plug group patients requested re-application of plugs despite dry eye symptoms that existed after 6 months in about 6 patients.

\section{DISCUSSION}

According to the International Dry Eye Workshop (DEWS), dry eye is defined as a multifactorial disease of tears and ocular surface with symptoms of visual disturbance, discomfort, and tear film instability with associated ocular inflammation and increased tear film osmolarity [16]. LASIK surgery is known to cause dry eye manifestations; post-LASIK dry eye symptoms may include burning sensations, heavy eyes, aching or sore sensation, red eye, reflex tearing and even blurring of vision. [17] Both botulinum toxin-induced punctal ectropion and punctal occlusion with plugs prolong the effects of lubricants and preserves natural tears.

This study directly compares botulinum toxin injection with punctal plugs for the 
Table 1 TBUT, Schirmer test, OSDI score and frequency of use of lubricant eye drops among the three groups at each follow-up visit

\begin{tabular}{|c|c|c|c|c|c|}
\hline & $\begin{array}{l}\text { Group A } \\
\text { (control) }\end{array}$ & Group B (BTA) & Group C (plugs) & $\begin{array}{l}\text { F/ } \\
\text { Kruskal-Wallis }\end{array}$ & $P$ value \\
\hline \multicolumn{6}{|l|}{2 weeks } \\
\hline TBUT & $4.95 \pm 1.49 \mathrm{~s}$ & $7.12 \pm 1.33 \mathrm{~s}$ & $6.87 \pm 1.76 s$ & 11.935 & $<0.0001$ \\
\hline \multirow[t]{2}{*}{ Schirmer test } & $4.64 \pm 2.11 \mathrm{~mm}$ & $8.4 \pm 4.37 \mathrm{~mm}$ & $7.63 \pm 3.15 \mathrm{~mm}$ & 7.07 & 0.002 \\
\hline & $4.32(1.98-8.3)$ & $8.9(3.1-16.7)$ & $7.42(3.1-14.2)$ & & \\
\hline \multirow[t]{2}{*}{ OSDI score } & $25.29 \pm 11.8$ & $12.33 \pm 8.59$ & $15.65 \pm 10.4$ & 12.273 & $<0.0001$ \\
\hline & $24(7.4-46.8)$ & $11.8(2.2-28.7)$ & $16(4.3-35.8)$ & 4.530 & \\
\hline \multirow{2}{*}{$\begin{array}{l}\text { Number of times of lubricants } \\
\text { use/day }\end{array}$} & $8.22 \pm 2.19$ & $5.71 \pm 3.10$ & $6.28 \pm 2.92$ & & 0.015 \\
\hline & $8(4-13)$ & $5(1-10)$ & $6(2-11)$ & & \\
\hline \multicolumn{6}{|l|}{6 weeks } \\
\hline \multirow[t]{2}{*}{ TBUT } & $4.94 \pm 1.23 \mathrm{~s}$ & $7.01 \pm 1.61 \mathrm{~s}$ & $6.92 \pm 2.27 s$ & 6.974 & 0.002 \\
\hline & & & & 6.551 & \\
\hline \multirow[t]{2}{*}{ Schirmer test } & $5.14 \pm 1.91 \mathrm{~mm}$ & $8.4 \pm 4.37 \mathrm{~mm}$ & $8.87 \pm 3.88 \mathrm{~mm}$ & & 0.003 \\
\hline & $5(2-8)$ & $8(3-16)$ & $9(3-15)$ & & \\
\hline \multirow[t]{2}{*}{ OSDI score } & $24.11 \pm 9.33$ & $11.57 \pm 7.83$ & $13.98 \pm 8.72$ & 11.840 & $<0.0001$ \\
\hline & $24(4-41)$ & $12(2-33)$ & $14.5(3-38)$ & 3.939 & \\
\hline \multirow{2}{*}{$\begin{array}{l}\text { Number of times of lubricants } \\
\text { use/day }\end{array}$} & $6.36 \pm 2.47$ & $4.57 \pm 2.16$ & $4.11 \pm 3.28$ & & 0.025 \\
\hline & $6(2-12)$ & $5(1-10)$ & $4(1-9)$ & & \\
\hline \multicolumn{6}{|l|}{3 months } \\
\hline TBUT & $8.17 \pm 2.02 \mathrm{~s}$ & $8.77 \pm 1.42 \mathrm{~s}$ & $9.33 \pm 2.39 \mathrm{~s}$ & 1.710 & 0.190 \\
\hline Schirmer test & $9.77 \pm 1.63 \mathrm{~mm}$ & $10.48 \pm 3.86 \mathrm{~mm}$ & $10.4 \pm 3.66 \mathrm{~mm}$ & 0.231 & 0.794 \\
\hline \multirow[t]{2}{*}{ OSDI score } & $15.18 \pm 5.63$ & $11.22 \pm 4.98$ & $12.42 \pm 8.31$ & 1.970 & 0.149 \\
\hline & $15(6-25)$ & $11(3-19)$ & $13(4-23)$ & 0.717 & 0.493 \\
\hline \multirow{2}{*}{$\begin{array}{l}\text { Number of times of lubricants } \\
\text { use/day }\end{array}$} & $3.52 \pm 2.15$ & $2.59 \pm 2.83$ & $2.93 \pm 2.43$ & & \\
\hline & $4(1-8)$ & $2(1-6)$ & $3(1-7)$ & & \\
\hline \multicolumn{6}{|l|}{6 months } \\
\hline TBUT & $8.98 \pm 2.23 \mathrm{~s}$ & $8.90 \pm 2.01 \mathrm{~s}$ & $9.05 \pm 1.76 s$ & 0.028 & 0.972 \\
\hline Schirmer test & $10.24 \pm 1.91 \mathrm{~mm}$ & $11.02 \pm 3.37 \mathrm{~mm}$ & $11.04 \pm 3.56 \mathrm{~mm}$ & 0.353 & 0.704 \\
\hline OSDI score & $12.74 \pm 4.16$ & $11.12 \pm 3.26$ & $11.81 \pm 3.20$ & 0.601 & 0.552 \\
\hline \multirow{2}{*}{$\begin{array}{l}\text { Number of times of lubricants } \\
\text { use/day }\end{array}$} & $2.41 \pm 1.62$ & $1.92 \pm 2.20$ & $1.76 \pm 2.32$ & 0.536 & \\
\hline & $2(1-6)$ & $1(1-5)$ & $1(1-5)$ & & 0.588 \\
\hline
\end{tabular}


Table 2 Complications of both botulinum toxin and punctal plugs

\begin{tabular}{llll}
\hline Complication & Number (\%) & $P$ \\
\cline { 2 - 3 } & Group B (botulinum toxin) & Group C (plugs) & $\mathbf{0 . 0 3 1 1}$ \\
\hline None & $15(75 \%)$ & $8(40 \%)$ \\
Irritation & $3(15 \%)$ & $6(30 \%)$ \\
Extrusion & 0 & $6(30 \%)$ \\
Decreased blinking power & $2(10 \%)$ & 0 \\
Total number of patient complications $(\%)$ & $7(35 \%)$ & $10(55 \%)$ \\
\hline
\end{tabular}

control of post-LASIK dry eye manifestations. Using these two methods of treatment carries the potential advantage of their temporary effect that suits the temporary nature of this particular type of dry eye. Silicone plugs were chosen because of their relative availability and their typical persistence for a longer period than collagen plugs; so, they are, theoretically, more suitable for comparison with BTA injections as they both last for a similar duration.

In this study, all the dry eye parameters were better for the BTA and plug group than the tear substitute eye drops-only group in the early post-operative period. Then, the differences became statistically insignificant starting from the 3rd month which could be attributed to the fading out of BTA effect and the expected improvement of the post-LASIK dry eye condition with regeneration of the neurotrophic corneal neurons.

Although the two methods of intervention carry a risk of potential complications, their significant effect in the reduction of post-LASIK dry eye manifestations makes them a valuable tool in our armamentorium for the management of this complication, especially in the first 3 months following LASIK, taking into account that the effect of these interventions fades away after 3 months with similar effects from tear substitutes in controlling any residual dry eye manifestations.

Sahlin et al. [18] were the first to study the effect of botulinum toxin injection on tear drainage in patients with dry eye. According to their study, limiting the toxin injection into the lower eye lid carried better results regarding the patient satisfaction. They attributed this to the minimal upper eyelid retraction that was encountered after the injection into both upper and lower eye lid and to the exaggerated weakening of the blink power causing some ocular irritation.

Isshiki et al. [19] found that there is significant improvement in both the Schirmer test and TBUT test results with reduction in high-order ocular aberrations in patients of blepharospasm treated with botulinum toxin. In addition to the previously mentioned tests, Park et al. [20] added lower lid tear meniscus height measured by optical coherence tomography and dacryoscintigraphy using $99 \mathrm{~m}$ technetium pertechnetate with similar results, confirming the improvement of dry eye manifestations after BTA injection in blepharospasm patients. Serna-Ojeda et al. [21] studied the effect of BTA injection on TBUT, Schirmer's test and corneal and conjunctival staining by performing a comparative eye-to-eye interventional study. They found that the eyes in the active treatment group showed better scores compared with the sham group with no adverse events reported.

On the other hand, Price et al. [22] and Horwath-Winter et al. [23] did not find any improvement of in the dry eye disease symptoms nor Schirmer test results among their patients who suffered from both dry eye disease and blepharospasm after they received BTA injections for treatment of blepharospasm, and this was attributed to the inhibitory effect of botulinum toxin on the secretion of the lacrimal gland as treatment of the aforementioned facial dystonias involved injection of the toxin in areas close to the lacrimal gland carrying the risk of diffusion of the toxin to the gland. 
Alfawaz et al. [24] evaluated the effect of punctal plug use in preventing dry eyes after LASIK by comparing the results of the TBUT test, Schirmer's test and OSDI in both eyes of the same patient treated with a lower punctal plug in one eye and using the other eye as control. They concluded that insertion of punctal plugs was significantly effective in improving dry eye symptoms and patient satisfaction after LASIK. Bukhari [25] compared both the botulinum toxin with the punctal plugs in the management of patients with severe dry eye that is not controlled by the standard topical medication. In her study, the patient satisfaction was significantly higher in the botulinum toxin group with better control of symptoms and fewer side-effects.

To our knowledge, this study is the first to introduce botulinum toxin injection for the control of post-LASIK dry eye which is a particular entity of dry eye due to its temporary nature and the relatively younger age group than the majority of dry eye patients.

One of the limitations of this study is that the comparison between different degrees of dry eye severity and to which extent did each degree of severity improve on each modality of treatment was not possible, because the interference was done in advance during the initial LASIK surgery as the post-LASIK dry eye is nearly a universal finding and the aim of our interventions was to improve the patient satisfaction in the first 3 months following LASIK, during which dry eye manifestations are expected to be maximum. Another limitation of the study is the small sample size.

Future studies comparing the effect of BTA and plugs on post-LASIK dry eye should be conducted, taking into account the introduction of the two methods after actual development of post-LASIK dry eye and thus allowing classification of the dry eye according to severity to assess which patients (moderate vs. severe) might obtain the most benefits from the proposed treatments.

\section{CONCLUSION}

The use of BTA injection to control dry eye symptoms by inducing temporary punctal ectropion is an effective method to improve the patient satisfaction after LASIK eye surgery. It has a higher level of patient satisfaction and fewer complications in comparison to punctal plugs or topical standard dry eye treatment.

\section{ACKNOWLEDGMENTS}

No funding or sponsorship was received for this study or publication of this article.

Both authors meet the International Committee of Medical Journal Editors (ICMJE) criteria for authorship for this manuscript, take responsibility for the integrity of the work as a whole, and have given final approval for the version to be published.

Compliance with ethics guidelines. All procedures followed were in accordance with the ethical standards of the responsible committee on human experimentation (institutional and national) and with the Helsinki Declaration of 1964, as revised in 2013. Informed consent was obtained from all patients for being included in the study.

Disclosures. Both authors (Fouda SM and Mattout HK) have no interests in any material or products mentioned in this study. No funding or sponsorship was received for this study or publication of this article.

Data availability. The datasets during and/ or analyzed during the current study are available from the corresponding author on reasonable request.

Open Access. This article is distributed under the terms of the Creative Commons Attribution-NonCommercial 4.0 International License (http://creativecommons.org/licenses/ by-nc/4.0/), which permits any noncommercial use, distribution, and reproduction in any medium, provided you give appropriate credit to the original author(s) and the source, provide a link to the Creative Commons license, and indicate if changes were made. 


\section{REFERENCES}

1. Levitt AE, Galor A, Weiss JS, Felix ER, Martin ER, Patin DJ, Sarantopoulos KD, Levitt RC. Chronic dry eye symptoms after LASIK: parallels and lessons to be learned from other persistent post-operative pain disorders. Mol Pain. 2015;11:21.

2. Probst EP. Lasik complications. In: Brightbill FS, Mcdonnell PJ, Mcghee CNJ et al (ed) Corneal surgery, 4th edition. USA: Mosby Elsevier; 2009, p. $827-849$.

3. Azuma M, Yabuta C, Fraunfelder FW, Shearer TR. Dry eye in lasik patients. BMC Res Notes. 2014;7:420-3.

4. Bae SH, Shina YJ, Kim HK, Hyon JY, Wee WR, Park SG. Vitamin D supplementation for patients with dry eye syndrome refractory to conventional treatment. Sci Rep. 2016;6:33083.

5. Lipham WJ. A brief history of the clinical applications of botulinum toxin. In: Lipham WJ, editor. Cosmetic and clinical applications of Botox and dermal fillers. 2nd ed. USA: Slack Inc.; 2008. p. 1-64.

6. Naik MN, Soparker CNS, Murphy R, Honavar SG. Botulinum toxin in ophthalmic plastic surgery. Indian J Ophthalmol. 2005;53:279-88.

7. Nigam PK, Migam A. Botulinum toxin. Indian J Dermatol. 2010;55(1):8-14.

8. Foster JA, Huang W, Perry JD, Holck DEE, Wulc AE. Cosmetic uses of Botulinum toxin. In: Levine MR, editor. Manual of oculoplastic surgery. Elsevier: New York; 2006. p. 93-7.

9. Dressler D. Botulinum toxin drugs: future developments. J Neural Transm. 2008;115:575-7.

10. Marcet MM, Shtein RM, Bradley EA, Deng SX, Meyer DR, Bilyk JR, Yen MT, Lee WB, Mawn LA. Safety and efficacy of lacrimal drainage system plugs for dry eye syndrome: a report by the American Academy Of Ophthalmology. Ophthalmology. 2015;122(8):1681-7.

11. Jehangir N, Bever G, Mahmood SM and Moshirfar M. Comprehensive review of the literature on existing punctal plugs for the management of dry eye disease. J Ophthalmol. 2016;9312340. doi:10. 1155/2016/9312340. (Epub 2016 Mar 7)

12. Yellepeddi VK, Sheshala R, McMillan H, Gujral C, Jones D, Raghu Raj Singh T. Punctal plug: a medical device to treat dry eye syndrome and for sustained drug delivery to the eye. Drug Disc Today, 2015;20(7):884-889.
13. Tong L, Beuerman R, Simonyi S, Hollander DA, Stern ME. Effects of punctal occlusion on clinical signs and symptoms and on tear cytokine levels in patients with dry eye. Ocul Surf. 2016;14(2):233-41.

14. Savini $G$, et al. The challenge of dry eye diagnosis. Clin Ophthalmol. 2008;2:31-55.

15. Schiffman RM, et al. Reliability and validity of the ocular surface disease index. Arch Ophthalmol. 2000;118:615-21.

16. Listed NA. The definition and classification of dry eye disease: report of the definition and classification subcommittee of the international dry eye workshop. Ocul Surf. 2007;5(2):75-92.

17. Adler R. Dry eyes; understanding dry eye syndrome. Highlights Ophthalmol. 2016;44(1):21-4.

18. Sahlin S, Chen E, Kaugesaar T, Almqvist H, Kjellberg $\mathrm{K}$, Lennerstrand G. Effect of eyelid botulinum toxin injection on lacrimal drainage. Am J Ophthalmol. 2000;129(4):481-6.

19. Isshiki $Y$, Ishikawa $H$, Mimura O. Changes in ocular higher-order aberrations following botulinum toxin treatment in patients with blepharospasm: BTX improves dry eye in patients with BEB. Jpn J Ophthalmol. 2016;60(6):486-91.

20. Serna-Ojeda JC. Nava-Castaneda. Paralysis of the orbicularis muscle of the eye using botulinum toxin type $\mathrm{A}$ in the treatment for dry eye. Acta Ophthalmol. 2016. doi:10.1111/aos.13140.

21. Park DI, Shin HM, Lee SY, Lew H. Tear production and drainage after botulinum toxin A injection in patients with essential blepharospasm. Acta Ophthalmol. 2013;91(2):108-12.

22. Price J, O'Day J. A comparative study of tear secretion in belpharospasm and hemifacial spasm patients treated with Botulinum toxin. J Clin Neuroopthalmol. 1993;13:67-71.

23. Horwath-Winter J, Bergloeff J, Haller-Schober E, Schmut O. Botulinum toxin A treatment in patients suffering from belpharospasm and dry eye. $\mathrm{Br} \mathrm{J}$ Ophthalmol. 2003;87:54-6.

24. Alfawaz AM, Algehedan S, Jastaneiah SS, Al-Mansouri S, Mousa A, Al-Assiri A. Efficacy of punctal occlusion in management of dry eyes after laser in situ keratomileusis for myopia. Curr Eye Res. 2014;39(3):257-62.

25. Bukhari AA. Botulinum neurotoxin type A versus punctal plug insertion in the management of dry eye disease. Oman J Ophthalmol. 2014;7:61-5. 